\title{
Cytotoxic activity of the amphibian ribonucleases onconase and r-amphinase on tumor cells from B cell lymphoproliferative disorders
}

\author{
PIOTR SMOLEWSKI $^{1}$, MAGDALENA WITKOWSKA ${ }^{1,2}$, MALGORZATAZWOLINSKA $^{1,2}$, \\ BARBARA CEBULA-OBRZUT ${ }^{1}$, AGATA MAJCHRZAK ${ }^{1}$, ALEKSANDRA JESKE ${ }^{1}$, \\ ZBIGNIEW DARZYNKIEWICZ ${ }^{3}$, WOJCIECH ARDELT ${ }^{4}$, \\ BARBARA ARDELT ${ }^{4}$ and TADEUSZ ROBAK ${ }^{2}$
}

\begin{abstract}
Departments of ${ }^{1}$ Experimental Hematology and ${ }^{2}$ Hematology, Medical University of Lodz, Copernicus Memorial Hospital, Lodz, Poland; ${ }^{3}$ The Brander Cancer Research Institute, New York Medical College, Valhalla, NY;

${ }^{4}$ TAmiR Biotechnology, Inc, Somerset, NJ, USA
\end{abstract}

Received December 7, 2013; Accepted January 3, 2014

DOI: $10.3892 /$ ijo.2014.2405

\begin{abstract}
Although major advancements in antitumor treatment have been observed, several B cell-derived malignancies still remain incurable. A promising approach that involves targeting RNA either by the use of specific antisense oligonucleotides or cytostatic/cytotoxic ribonucleases (RNases) is being promoted. Two amphibian RNases, onconase (ONC; ranpirnase) and, more recently, r-amphinase (r-Amph), have already been tested, but thus far, mostly on solid tumors. In this study, for the first time we provide comprehensive data on ex vivo and in vivo cytotoxic activity of ONC or r-Amph against cancer cells from different B cell lymphoid malignancies, together with their detailed mode of antitumor action. Our data revealed strong pro-apoptotic activity of ONC and r-Amph in both chronic lymphocytic leukemia and aggressive B cell lymphomas, with less impact on acute lymphoblastic leukemia or multiple myeloma cells. Moreover, the antitumor action of ONC and r-Amph was markedly selective against neoplastic cells sparing normal, healthy control-derived lymphocytes.
\end{abstract}

\section{Introduction}

Antitumor ribonucleases (RNases) are promising family of small (10-28 kDa) basic proteins with strong anticancer potential (1). As a whole this superfamily of secretory enzymes is responsible for operating at the crossroads of transcription and translation. After early enthusiasm, their anticancer

Correspondence to: Professor Piotr Smolewski, Department of Experimental Hematology, Medical University of Lodz, Copernicus Memorial Hospital, Ciołkowskiego 2, 93-510 Lodz, Poland

E-mail: piotr_smolewski@wp.pl

Key words: onconase, r-amphinase, Rana pipiens, apoptosis, anticancer properties potential in terms of clinical utility suffered a decline until quite recently, when they have attracted attention again, due to discovery of their remarkable and complex biological activities (2,3). Among various RNases described thus far, only some of them were found to be toxic to cancer cells. The best known and widely investigated is onconase (ONC), which has reached the late-stage clinical trials for treatment of malignant mesothelioma (4). More recently described amphinase (Amph) as well as its recombinant form (r-Amph) also display both cytotoxic and cytostatic effects (5).

ONC and Amph were discovered and sequenced by Alfacell Corporation (currently TAmiR Biotechnology, Inc, Somerset, NJ, USA), the first one more than two decades ago (6) while the latter more recently (5). Both enzymes were isolated from oocytes of leopard frog Rana pipiens. Amph is the largest among frog homologues of RNase A and consists of 114 amino acid residues (5) while ONC, on the other hand, is the smallest of whole superfamily having only 104 amino acid residues (7).

The cytostatic and cytotoxic properties of ONC and r-Amph depend on their enzymatic activity targeting the crossroads between transcription and translation and catalyzing RNA degradation (8). It was initially considered, that the key target are rRNA and/or tRNA as their degradation led to inhibition of protein synthesis. According to recent findings, however, the suspected target of RNases can also be the noncoding RNA (microRNAs), which is responsible for regulation of gene expression through RNA interference (RNAi) (9). Consistent with the latter, they can modulate the process of cell differentiation in the early embryos by targeting strictly RNAi.

Although a major advancement in antitumor treatment has been observed, still several B cell-derived malignancies remain incurable. A promising approach is the one involving targeting of RNA. Of particular interest are numerous observations that ONC acts strongly synergistic while combined with one of the several different antitumor drugs. This was observed in vitro 
in combination with the agents used during standard treatment such as tamoxifen or trifluoroperazine (10) in solid tumors. Interestingly, in combination with vincristine, ONC has shown high toxicity even against multi-drug resistant cancer cells (11).

No previous report exists on the activity of ONC or r-Amph in combination with standard cytostatic treatment against B cell malignant disorders such as CLL or non-Hodgkin's lymphoma. In the present study we observed that both ONC and $\mathrm{r}$-Amph, alone or in combination with routinely used cytostatics has marked toxicity against investigated cancer cells.

\section{Materials and methods}

Peripheral blood mononuclear cell (PBMC) isolation. Peripheral blood samples were obtained from untreated patients with chronic lymphocytic leukemia (CLL) and acute lymphoblastic leukemia (ALL).

The CLL group consisted of 45 patients, 21 women and 34 men, median age 70.1 (range 51-85 years). There were 21 patients in stage 0 -I according to Rai classification, 11 patients in stage II and 13 in stage III-IV. Twenty-seven patients were stable and 18 had progressive disease. Three out of 45 patients had $17 \mathrm{p} 13$ deletion, $5 / 45$ had $11 \mathrm{q}$ region deletion or translocation. In 10/45 CLL cells were ZAP-70-positive and 14/45 showed CD38-positivity.

The ALL group consisted of 15 patients, 10 women and 5 men, median age 37.5 (range 19-48 years). Two out of 15 patients were Philadelphia-positive; hyperploid was found in 10/45 patients. Median white blood cell count was $27.3 \mathrm{G} / \mathrm{L}$ (14-125 G/L).

Lymphocytes obtained from 31 healthy volunteers were also treated with the studied drugs. PBMC were isolated from heparinized blood samples from CLL and ALL patients by centrifugation in Histopaque-1077 (Sigma Diagnostic, St. Louis, MO, USA) density gradients. A 1:1 (v/v) mixture of blood and Hanks' balanced salt solution (HBSS; Biomed, Lublin, Poland) was layered on the top of the Histopaque media in centrifuge tubes and centrifuged for $30 \mathrm{~min}$ at $200 \mathrm{x} \mathrm{g}$. The interphase region containing PBMC was collected and then washed twice, in HBSS and RPMI-1640 medium. Next, the cells were resuspended in RPMI-1640 $\left(0.5 \times 10^{6}\right.$ cells $\left./ \mathrm{ml}\right) ; 1 \mathrm{ml}$ aliquots of cell suspensions were placed into 24-culture well dishes (Nunc, Roskilde, Denmark) for further cultures.

Additionally, we tested in vitro activity of ONC or r-Amph alone or in combination with doxorubicin (DOX) on cell lines derived from Burkitt's lymphoma (Raji), diffuse large B cell lymphoma (DLBCL)-derived cells (Toledo) or with DEX on multiple myeloma (MM)-derived cell line (RPMI 8226). All cell lines were purchased from American Type Culture Collection (ATCC, Manassas, VA, USA).

At the $0 \mathrm{~h}$ time point and after $72 \mathrm{~h}$ CLL or ALL PBMCs or cells from the cell lines were subjected to a simultaneous assessment of cytotoxicity and apoptosis. Cells were incubated for $72 \mathrm{~h}$ with ONC or $\mathrm{r}-\mathrm{Amph}$, the drugs kindly provided by TAmiR Biotechnology, Inc, Somerset, NJ, USA (previously Alfacell Corporation, Somerset, NJ, USA). At first the drugs were applied at final concentration range between $1 \mu \mathrm{g} / \mathrm{ml}$ to $50 \mu \mathrm{g} / \mathrm{ml}$, and subsequently the minimal concentrations that exerted significant increase in cytotoxicity, compared to untreated control samples, were selected for further studies (Table I). Experiments on ex vivo cells were made in triplicates. In case of cell lines each experiment was repeated at least 5 times.

Cell cultures were maintained in RPMI-1640 medium containing $10 \%(\mathrm{v} / \mathrm{v})$ heat inactivated fetal calf serum (FCS) and antibiotics (streptomycin $50 \mathrm{mg} / \mathrm{ml}$, penicillin $50 \mathrm{IU} /$ $\mathrm{ml}$; Life Technologies, Paisley, UK), at $37^{\circ} \mathrm{C}, 5 \% \mathrm{CO}_{2}$, fully humidified. Cells were incubated in $25-\mathrm{ml}$ dishes (Nunc), in concentration $0.2 \times 10^{6} / \mathrm{ml}$. Viability of Toledo cells before culturing was $95 \%$ or more.

Assessment of cytotoxicity. Cytotoxicity was assessed using the propidium iodide (PI) exclusion test. Namely, after incubation with drugs, cells were washed twice in PBS and stained in $0.5 \mathrm{ml}$ of $10 \mu \mathrm{g} / \mathrm{ml}$ PI solution in PBS (room temperature, in the dark). Then, the cell fluorescence was measured by flow cytometry, using the FL3 fluorescence emission filter; PI-positive cells were defined as non-viable.

Assessment of apoptosis. Drug-induced apoptosis was assessed finally after $72 \mathrm{~h}$ of incubation by the flow cytometry, using Annexin V (Ann V) assay. After incubation with drugs cells were washed with PBS and then re-suspended in $100 \mu 1$ of binding buffer, containing $2 \mu \mathrm{l}$ of FITC conjugated Ann V and $10 \mu \mathrm{g} / \mathrm{ml}$ of PI (Becton-Dickinson, San Jose, CA, USA). Then, samples were incubated for $15 \mathrm{~min}$ (room temperature, in the dark). The fluorescence was measured by flow cytometer using FL1 (Ann V) and FL3 (PI) standard emission filters. Apoptotic index (AI) was calculated as a percentage Ann V-positive $\left(\right.$ Ann $\left.\mathrm{V}^{+}\right)$cells.

Mechanisms of apoptosis activation. Activation of caspases $-8,-9$ and -3 , a decline of mitochondrial potential $(\Delta \Psi \mathrm{m})$ and expression of several apoptosis-regulating proteins were investigated.

Detection of activated caspases. Caspase-3 activation was detected using FITC-conjugated monoclonal rabbit anti-active caspase-3 antibody (BD Pharmingen, San Diego, CA, USA). After incubation cells were fixed and permeabilized using Cytofix/Cytoperm ${ }^{\mathrm{TM}}$ (BD Pharmingen) solution (20 min on ice), then washed twice and re-suspended in the Perm/Wash ${ }^{\mathrm{TM}}$ buffer (BD Pharmingen). The antibody was added as $60 \mu 1$ per $300 \mu \mathrm{l}$ of cell suspension (30-min incubation at RT). The fluorescence was measured directly after staining and washing in Perm/Wash buffer by flow cytometry using FL1 filter for detecting the green fluorescence of anti-active caspase- 3 antibody.

Activation of other caspases was detected using FLICA methodology (12). Commercially available FAM-LETD-FMK FLICA $^{\mathrm{TM}}$ Caspase-8 assay kit and FAM-LEHD-FMK Reagent-9 FLICA ${ }^{\mathrm{TM}}$ Caspase-9 assay kit were used for assessment of caspase- 8 and caspase- 9 activation. Initially prepared, $150 \mathrm{X}$ concentrated solution in dimethylsulphoxide (DMSO; Sigma-Aldrich, St. Louis, MO, USA) were stored at $-20^{\circ} \mathrm{C}$, protected from light. Directly before use, the aliquots were diluted in PBS (1:5), then added to $300 \mu 1$ of culture to obtain a $10 \mu \mathrm{M}$ concentration of FAM-LETD-FMK (for caspase-8 detection) or FAM-LEDH-FMK (for caspase-9 detection), respectively. Cultures were terminated by washing the cells twice ( $5 \mathrm{~min}, 140 \mathrm{x} \mathrm{g}$ ) with the 'wash buffer'. After centrifu- 
Table I. Choosing of optimal onconase (ONC) and r-amphinase (r-Amph) doses for further experiments in different tumor cell models. The lowest drug doses exerting significant cytotoxic effect compared to the untreated control samples were chosen for further experiment as an optimal concentrations.

\begin{tabular}{|c|c|c|c|c|c|c|c|c|c|c|c|c|c|c|}
\hline \multirow[b]{2}{*}{ Cells } & \multicolumn{2}{|c|}{$1 \mu \mathrm{g} / \mathrm{ml}$} & \multicolumn{2}{|c|}{$5 \mu \mathrm{g} / \mathrm{ml}$} & \multicolumn{2}{|c|}{$10 \mu \mathrm{g} / \mathrm{ml}$} & \multicolumn{2}{|c|}{$20 \mu \mathrm{g} / \mathrm{ml}$} & \multicolumn{2}{|c|}{$30 \mu \mathrm{g} / \mathrm{ml}$} & \multicolumn{2}{|c|}{$40 \mu \mathrm{g} / \mathrm{ml}$} & \multicolumn{2}{|c|}{$50 \mu \mathrm{g} / \mathrm{ml}$} \\
\hline & ONC & r-Amph & ONC & r-Amph & $\mathrm{ONC}$ & r-Amph & ONC & r-Amph & ONC & r-Amph & ONC & -Amph & ONC & Amph \\
\hline CLL & NS & NS & $*$ & NS & $\rightarrow$ & $*$ & $\rightarrow$ & $\rightarrow$ & $\rightarrow$ & $\rightarrow$ & $\rightarrow$ & $\rightarrow$ & $\rightarrow$ & $\rightarrow$ \\
\hline ALL & NS & NS & NS & NS & NS & NS & $*$ & NS & $\rightarrow$ & NS & $\rightarrow$ & $*$ & $\rightarrow$ & $\rightarrow$ \\
\hline Toledo & $*$ & NS & $\rightarrow$ & NS & $\rightarrow$ & $*$ & $\rightarrow$ & $\rightarrow$ & $\rightarrow$ & $\rightarrow$ & $\rightarrow$ & $\rightarrow$ & $\rightarrow$ & $\rightarrow$ \\
\hline Raji & NS & NS & NS & NS & NS & NS & $*$ & NS & $\rightarrow$ & NS & $\rightarrow$ & * & $\rightarrow$ & $\rightarrow$ \\
\hline RPMI 8226 & NS & NS & NS & NS & NS & NS & NS & NS & * & NS & $\rightarrow$ & * & $\rightarrow$ & $\rightarrow$ \\
\hline
\end{tabular}

*The lowest dose of RNases exerting statistically significant increase in cytotoxicity on tumor cells comparing to untreated, control samples (chosen as an 'optimal' for further experiments). $\rightarrow$ Higher doses of RNases exerting statistically significant increase in cytotoxicity on tumor cells. NS, not significant; CLL, chronic lymphocytic leukemia; ALL, acute lymbphoblastic leukemia; Toledo, diffuse large B cell lymphomaderived cell line; Raji, Burkitt's lymphoma-derived cell line; RPMI 8226, multiple myeloma-derived cell line.

gation, the pellets were re-suspended in $1 \mathrm{ml}$ of wash buffer and the samples were placed on ice. Cell fluorescence derived from FAM-LETD-FMK or FAM-LEDH-FMK was measured during the next 15 min by flow cytometry.

Dissipation of mitochondrial potential $(\Delta \Psi m)$. MitoTracker Red 580 dye (Molecular Probes, Eugene, OR, USA), which accumulates to active mitochondria of living cells, was used as a probe of $\Delta \Psi \mathrm{m}$. The stock solution of MitoTracker Red (1 mM) was diluted to concentration of $50 \mathrm{nM}$ by adding to the growth culture medium (20-min incubation, at room temperature). The decline of $\Delta \Psi \mathrm{m}$ was visualized by the decrease in red fluorescence of the dye, as detected by flow cytometry.

Expression of apoptosis-regulating proteins. Cellular expression of several apoptosis-regulating proteins, including Bcl-2 family (Bax, Bak, Bad, Bcl-2, Mcl-1), and inhibitor of apoptosis protein (IAP) family (cIAP1, cIAP2, survivin, XIAP and Smac/Diablo), were also investigated. Cells were fixed in $1 \%$ methanol-free paraformaldehyde and permabilized with $0.1 \%$ polysorbate-20 (Tween-20) in PBS. Anti-human Bax primary rabbit $\mathrm{Ab}$ (Dako, Glostrup, Denmark) was used in the dilution 1:100 (60-min incubation). Anti-Bak, anti-Bid and anti-Bad (all Abcam, Cambridge, UK) primary rabbit anti-human MoAbs were used in dilutions 1:10 (60-min incubation). Anti-Bcl-2 MoAb (Dako) was used in concentration 1:15 (30-min incubation). Mouse anti-Mcl-1 MoAb (Abcam) was used in 1:30 concentration (30 min). Mouse anti-human XIAP MoAb (Oncogene Res. Products, San Diego, CA, USA) was used in dilution 1:100 (incubation for $60 \mathrm{~min}$ ).

For assessment of IAPs and IAP antagonist expression the following Abs were used: anti-cIAP1, anti-Smac/Diablo, anti-survivin, rabbit polyclonal antibodies (PoAbs), anti-cIAP2, anti-XIAP goat PoAbs (all R\&D Systems, Minneapolis, MN, USA) in concentration of 1:100. All Abs were diluted in PBS containing $1 \%$ bovine serum albumin (BSA). Samples were incubated for $60 \mathrm{~min}$, at RT, then washed in PBS and subjected to centrifugation. Subsequently, they were incubated with the swine FITC-conjugated $\mathrm{Ab}$ anti-rabbit at 1:20 dilution for
$60 \mathrm{~min}$, at RT, in the dark. The cells were then washed and re-suspended in $400 \mu 1 \mathrm{PBS}$ and analyzed by cytometry. The increase or decrease in expression of the respective proteins measured as intensity of their immunofluorescence (MFI) and compared to control, then defined as up- or downregulation, respectively.

Fluorescence measurements. All fluorescence measurements were performed by flow cytometry (FACScan; Becton-Dickinson, San Jose, CA, USA), using standard emission filters: green $(\lambda=530 \pm 20 \mathrm{~nm}$; FL1), orange $(\lambda=$ 560-600 nm; FL2) and red ( $\lambda>600 \mathrm{~nm}$; FL3), where necessary. Ten thousand cells per sample were measured per each sample.

Statistics. The statistical analysis of data was performed using statistical software (Statistica v.7.0, Tulsa, OK, USA). The range of the measured variable, means and standard deviations (SD) as well as medians and ranges were calculated. The differences between values were evaluated with Student's t-test or by Mann-Whitney U test, as necessary. The Spearman's rank test was used for assessing correlations between some data. P-values $<0.05$ were considered to indicate a statistically significant difference.

\section{Results}

Cytotoxicity of the drugs. Based on preliminary studies on different ex vivo and in vitro experimental models, concentrations of $10-20 \mu \mathrm{g} / \mathrm{ml}$ of ONC and $20-60 \mu \mathrm{g} / \mathrm{ml}$ of r-Amph were chosen for final studies as the lowest doses inducing significant cytotoxic effect (Table I). In a similar manner concentrations $1 \mu \mathrm{g} / \mathrm{ml}$ of FA, $10 \mu \mathrm{g} / \mathrm{ml}$ of DOX and $20 \mu \mathrm{g} / \mathrm{ml}$ of DEX were selected.

Pro-apoptotic effects of ONC or $r$-Amph alone and in combination with other drugs. The level of cytotoxicity assessed by PI staining strongly correlated with AI evaluated by Ann V assay $(\mathrm{R}=0.93, \mathrm{p}<0.001)$. Thus, the mechanism of both ONC and r-Amph cytotoxicity in the examined models was induc- 

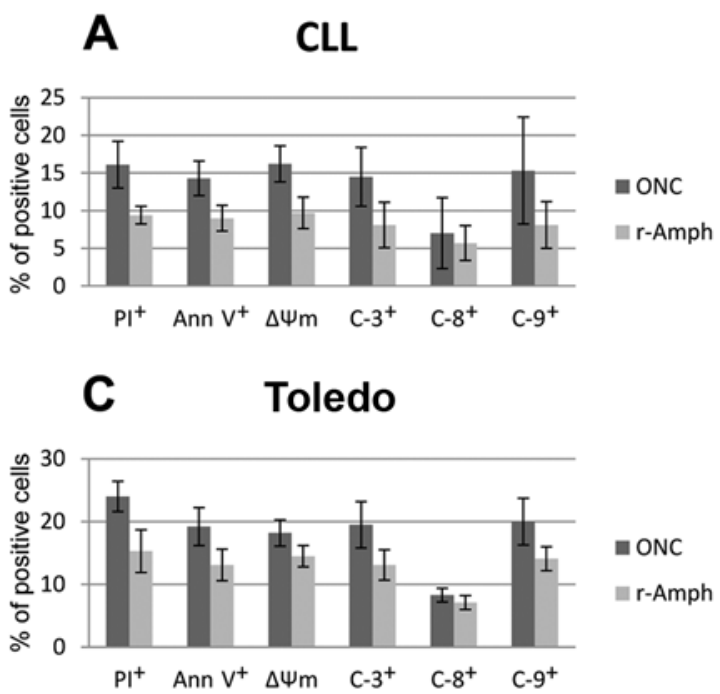

\section{B ALL}

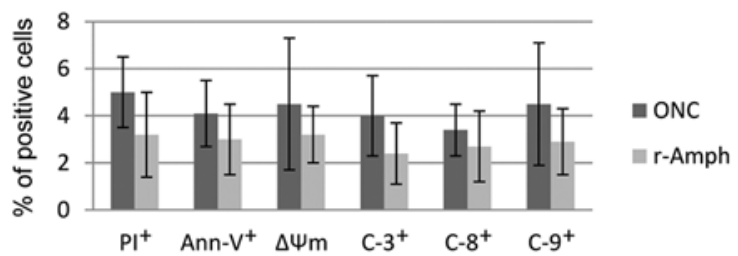

D Raji

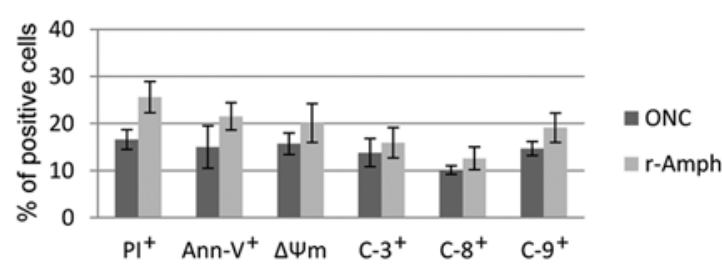

E RPMI 8226

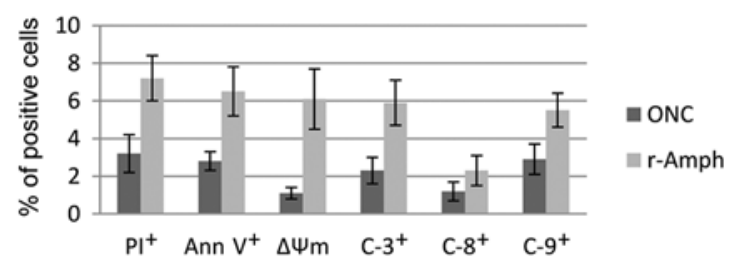

Figure 1. Cytotoxic and apoptotic effects of onconase (ONC) and r-amphinase (r-Amph). Cells from (A) chronic lymphocytic leukemia (CLL) and (B) acute lymphoblastic leukemia (ALL) patients, as well as cells derived from diffuse (C) large B cell lymphoma, Toledo, (D) Burkitt's lymphoma, Raji and (E) multiple myeloma, RPMI 8226 were treated for $72 \mathrm{~h}$. The figure shows percentages of propidium iodide (PI)-positive cells in drug-treated cultures, compensated by the rate of PI-positive cells from parallel, untreated control samples. The levels of significance are specified in Results.

tion of caspase-dependent apoptosis, with activation of both the external and internal caspase activation pathways (Fig. 1A).

In CLL cells, significant effect of both ONC and r-Amph was evident after $72 \mathrm{~h}$ of treatment (median AI 38.1\% and 31.5 , respectively; vs. untreated control cells; $\mathrm{p}=0.007$ and $\mathrm{p}=0.012$, respectively). Combination of ONC, but not r-Amph, with FA exerted significantly stronger effect than single drugs $(\mathrm{p}<0.005)$ (Fig. 2A).

In case of ALL cells we did not observe any significant cytotoxic activity of neither ONC nor r-Amph. Interestingly, ONC+DOX combination, but not r-Amph, showed significantly higher pro-apoptotic effect compared to the single agents $(p<0.005)$ (Fig. 2B).

Interestingly, both $\mathrm{ONC}$ and $\mathrm{r}-\mathrm{Amph}$ were highly active against the DLBCL-derived cell line Toledo, and even at the lowest concentrations induced significant toxicity. Mean AI for ONC 27.8 and $19.1 \%$, respectively; vs. untreated cells; $p=0.001$ and $\mathrm{p}=0.008$, respectively). Also, combinations of ONC or r-Amph with DOX induced significantly higher pro-apoptotic effect than single agents $(\mathrm{p}<0.003$ and $\mathrm{p}<0.013$, respectively) (Fig. 2C).

Both ONC and r-Amph showed significant antitumor activity in the Burkitt's lymphoma-derived cell line Raji (median AI 23.1 and 30.3\%, respectively; vs. control; $p=0.007$ and $p=0.001$, respectively). Combinations of either ONC or $\mathrm{r}$-Amph with DOX induced higher pro-apoptotic effects than single agents $(p<0.005$ and $p<0.001$, respectively) (Fig. 2D).
In MM cell line, RPMI 8226, only r-Amph alone induced significant cytotoxity vs. control as a single drug (mean AI $13.3 \%$; vs. untreated control cells; $\mathrm{p}=0.036)$. However, combination of both RNases with DEX exerted significantly higher effects compared to single drugs (for ONC+DEX $\mathrm{p}<0.01$; for r-Amph+DEX p<0.0009) (Fig. 2E).

Mechanisms of RNase-induced apoptosis. Apoptosis induced by both ONC and r-Amph was evidently dependent on both, mitochondrial and external caspase-activation pathways, inducing activation of caspases $-9,-8$ and -3 ; as well as decline of mitochondrial potential (Fig. 2).

Both ONC and r-Amph induced various effects on apoptosis-regulating proteins (Table II). In general, overexpression of Bax, except in ALL cells treated with r-Amph.

Other examined proteins show different level of expression in response to RNase treatment. Namely, in CLL cells treated with either ONC or $\mathrm{r}-\mathrm{Amph}$, despite the increase in Bax expression, downregulation or Mcl-1, CIAP1 and XIAP proteins was found.

In ALL cells treated with ONC, overexpression of Bax, together with a decrease in Bcl-2 and XIAP expression was found. In regard to $\mathrm{r}$-Amph only downregulation of XIAP protein was observed.

In Toledo cells ONC induced overexpression of Bax and Bad, and downregulation of XIAP protein. R-Amph exerted more effects on examined proteins, with increase of Bax and 

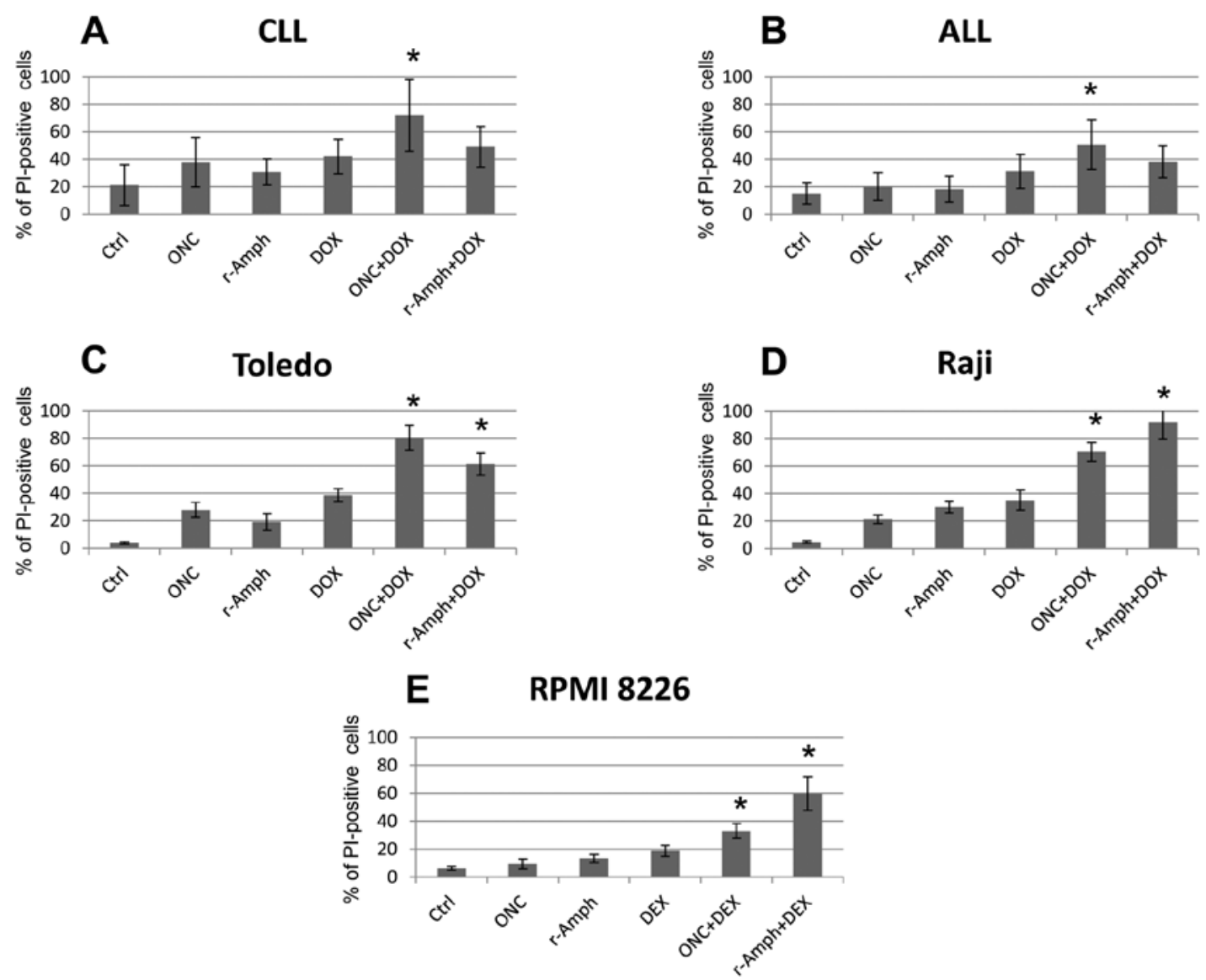

Figure 2. Cytotoxic effects of onconase (ONC) or r-amphinase (r-Amph) used alone and combination with other drugs. Cells from (A) chronic lymphocytic leukemia (CLL) and (B) acute lymphoblastic leukemia (ALL) patients, as well as cells derived from (C) diffuse large B cell lymphoma, Toledo, (D) Burkitt's lymphoma, Raji and (E) multiple myeloma, RPMI 8226 were treated for $72 \mathrm{~h}$ with either drugs alone or in combination with doxorubicin (DOX) or dexamethasone (DEX), when appropriate. "Significant differences in cytotoxicity of particular drug combinations vs. single agents are shown.

Bad, as well as decrease in Bcl-2, Mcl-2 and XIAP protein expression.

In Raji cell line, ONC enhanced Bax and decreased Bcl-2 levels, whereas r-Amph induced overexpression of Bax, Bak, Bad and Smac/Diablo (IAP antagonist) proteins.

In RPMI 8226 cells, ONC triggered increased expression of Bax and Bak, whereas decrease in Bcl-2 and survivin levels. In r-Amph-treated cells overexpression of Bax and Smac/ Diablo proteins was noted (Table II).

Effect of ONC and $r$-Amph on healthy lymphocytes. Importantly, ONC and to some extent r-Amph showed selective cytotoxicity on tumor cells, while sparing healthy cells. Namely, all doses of ONC used in different experimental models did not significantly affect survival of healthy lymphocytes. Similarly, the lower doses of r-Amph, up to $30 \mu \mathrm{g} / \mathrm{ml}$, did not exert significant cytotoxic effect on the same cells (Table III).

\section{Discussion}

Various novel agents are investigated for treatment of hematologic malignancies, as the current approaches are not curative. Despite great advances, there is still a group of patients, who achieve only partial response, or have refractory disease after the initial treatment. In this context, innovative and new treatment strategies are warranted. Great majority of the new anticancer drugs are targeting either DNA, specific receptors on cell surface or proteins with signal transduction properties that are overly activated in cancer. RNases, by targeting the post-transcriptional events, namely different species of RNA, including microRNAs, can be considered as the anticancer drugs with entirely new mechanism of action (7).

There is a growing body of evidence that prolonged exposure of cancer cells to ONC or r-Amph leads to apoptosis $(13,14)$. Induction of apoptosis is considered to be the predominant mechanism responsible for cytotoxic and cytostatic activity of both RNases. Cell death is manifested by typical morphologic changes and activation of caspases which provide the mechanism leading to cell demise. Whereas both ONC and Amph cause prolongation or arrest in G1 cycle phase and results in apoptosis that involves classical activation of endonucleases, caspases, transglutaminase and serine proteases (14). However in studies investigating mechanism of antitumor activity of ONC the caspase independent pathway was also recognized (15). Our present study reveals strong pro-apoptotic activity of ONC and r-Amph in both CLL and aggressive B cell lymphomas, with less evident impact for surviving of ALL or MM cells. The mechanism appears to depend on both the mitochondrial and external caspase-activation pathways since 
Table II. Apoptosis-regulating proteins.

A, Apoptosis-regulating protein expression in response to onconase (ONC).

\begin{tabular}{lcccccccccc}
\hline Cells & Bax & Bak & Bad & Bcl-2 & Mcl-1 & c-IAP1 & c-IAP2 & Survivin & XIAP & Smac-Diablo \\
\hline CLL & $\uparrow^{\mathrm{a}}$ & NS & NS & NS & $\downarrow^{\mathrm{a}}$ & $\downarrow^{\mathrm{a}}$ & NS & NS & $\downarrow^{\mathrm{a}}$ & NS \\
ALL & $\uparrow^{\mathrm{a}}$ & NS & NS & $\downarrow^{\mathrm{a}}$ & NS & NS & NS & NS & $\downarrow^{\mathrm{a}}$ & NS \\
Toledo & $\uparrow^{\mathrm{a}}$ & NS & $\uparrow^{\mathrm{a}}$ & NS & NS & NS & NS & NS & $\downarrow^{\mathrm{a}}$ & NS \\
Raji & $\uparrow^{\mathrm{a}}$ & NS & NS & $\downarrow^{\mathrm{a}}$ & NS & NS & NS & NS & NS & NS \\
RPMI 8226 & $\uparrow^{\mathrm{a}}$ & $\uparrow^{\mathrm{a}}$ & NS & $\downarrow^{\mathrm{a}}$ & NS & NS & NS & $\downarrow^{\mathrm{a}}$ & NS & NS \\
\hline
\end{tabular}

$\mathrm{B}$, Apoptosis-regulating protein expression in response to $\mathrm{r}$-amphinase (r-Amph).

\begin{tabular}{|c|c|c|c|c|c|c|c|c|c|c|}
\hline Cells & Bax & Bak & $\mathrm{Bad}$ & $\mathrm{Bcl}-2$ & Mcl-1 & c-IAP1 & c-IAP2 & Survivin & XIAP & Smac-Diablo \\
\hline CLL & $\uparrow^{\mathrm{a}}$ & NS & NS & NS & $\downarrow^{\mathrm{a}}$ & $\downarrow^{\mathrm{a}}$ & NS & NS & $\downarrow^{\mathrm{a}}$ & NS \\
\hline ALL & NS & NS & NS & NS & NS & NS & NS & NS & $\downarrow^{\mathrm{a}}$ & NS \\
\hline Toledo & $\uparrow^{\mathrm{a}}$ & NS & $\uparrow^{\mathrm{a}}$ & $\downarrow^{\mathrm{a}}$ & $\downarrow^{\mathrm{a}}$ & NS & NS & NS & $\downarrow^{\mathrm{a}}$ & NS \\
\hline Raji & $\uparrow^{\mathrm{a}}$ & $\uparrow^{\mathrm{a}}$ & $\uparrow^{\mathrm{a}}$ & NS & NS & NS & NS & NS & NS & $\uparrow^{\mathrm{a}}$ \\
\hline RPMI 8226 & $\uparrow^{\mathrm{a}}$ & NS & NS & NS & NS & NS & NS & NS & NS & $\uparrow^{\mathrm{a}}$ \\
\hline
\end{tabular}

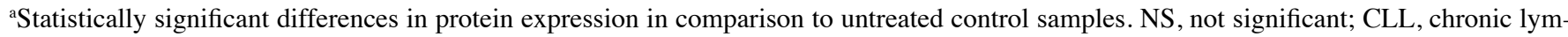
phocytic leukemia; ALL, acute lymphoblastic leukemia.

Table III. Cytotoxic effects ${ }^{\mathrm{a}}$ on healthy lymphocytes treated for $72 \mathrm{~h}$ with onconase (ONC) or r-amphinase (r-Amph) vs. untreated control samples (Ctrl).

\begin{tabular}{lcccc}
\hline RNase & & \multicolumn{2}{c}{ Drug doses } & Statistics \\
\hline ONC & $10 \mu \mathrm{g} / \mathrm{ml}$ & $20 \mu \mathrm{g} / \mathrm{ml}$ & $30 \mu \mathrm{g} / \mathrm{ml}$ & ONC vs. Ctrl \\
& $5.1 \pm 2.5^{\mathrm{b}}$ & $7.0 \pm 2.9^{\mathrm{b}}$ & $9.7 \pm 4.1^{\mathrm{b}}$ & \\
r-Amph & $10 \mu \mathrm{g} / \mathrm{ml}$ & $30 \mu \mathrm{g} / \mathrm{ml}$ & $60 \mu \mathrm{g} / \mathrm{ml}$ & r-Amph vs. Ctrl \\
& $4.8 \pm 1.1^{\mathrm{b}}$ & $6.75 \pm 2.1^{\mathrm{b}}$ & $17.7 \pm 4.7^{\mathrm{c}}$ & \\
\end{tabular}

${ }^{\text {aT }}$ The percentage of propidium iodide (PI)-positive cells in drug-treated samples corrected by the rate of unviable cells in parallel, untreated control samples. Means \pm standard deviations of unviable, PI-positive cells are shown. ${ }^{\mathrm{b}} \mathrm{p}>0.05 ;{ }^{\mathrm{c}} \mathrm{p}<0.05$.

caspases $-9,-8,-3$ are activated concurrently with a decline of mitochondrial potential. It should be noted, that specificity of FLICA reagents towards particular caspases is not absolute (16) and therefore activation of caspase-9 should be interpreted with caution. Moreover, in our study we observed overexpression of Bax and Bak proteins and downregulation of Bcl-2 expression in cells treated with either of the RNases. Interestingly, the concentrations of ONC used in different experimental models did not significantly affect the viability of normal lymphocytes.

In this study we demonstrated that both ONC and r-Amph have strong cytotoxic activity against cancer cells. Unlike most chemotherapeutic agents that act rather rapidly the effects of RNases can be observed after some delay (17). We observed significant effect of $72 \mathrm{~h}$ treatment of CLL cells with both RNases. In MM cells, only r-Amph alone induced signifi- cant cytotoxity vs. control ( $\mathrm{p}<0.05$ both in vitro and ex vivo). Both ONC and r-Amph showed significant antitumor activity in Burkitt's lymphoma-derived Raji cell line (vs. control; $\mathrm{p}=0.007$ and $\mathrm{p}=0,001$, respectively). The most sensitive was the DLBCL-derived cell line which responded to ONC as well as r-Amph; even at the lowest concentrations. It was crucial that, the same doses did not affect the survival of healthy lymphocytes.

The major advantage of $\mathrm{r}-\mathrm{Amph}$ and $\mathrm{ONC}$ over other anticancer treatment is their apparent preference to tumor cells (18). The mechanism responsible for this effect is still not entirely elucidated. The most probable explanation of this phenomenon may be related to cationic properties of RNases that favor their preferential binding to a negatively charged cell membrane. In cancer cells the level of sialic acid, rich in gangliosides, is higher which leads to electro-negativity of the plasma membrane. Because RNases are strongly cationic they have greater electrostatic affinity to the anionic surface and consequently are more avidly internalized by tumor cells (19). This results in their more effective attachment to cancer cells than to the normal ones. After traversing through the plasma membrane by endocytosis the RNases are released in the cytosol where RNA degradation occurs (20).

Of particular interest is the observation that $\mathrm{ONC}$ is strongly synergistic when combined with different well-characterized anticancer agents. Initially the synergism was observed on human lung carcinoma or pancreatic adenocarcinoma cell lines, when ONC was used in combination with either tamoxifen or trifluoroperazine (10). Subsequently, a series of investigations were carried out revealing a synergism or additive effects of ONC in combination with a variety of other widely used agents such as lovastatin (21), interferons or vincristine (10), tumor necrosis factor $\alpha(22)$ as well as cepharantine (23). The striking feature is that the observed 
synergisms were in combinations with different antitumor agents, characterized by a distinct mechanism of action. Such studies have not been performed with r-Amph thus far. It is likely that the mechanism behind the synergistic effect of ONC with respect to several antitumor drugs stems from the fact that ONC targets microRNAi $(8,24)$ and there is strong evidence that the multidrug resistance provided by the (ABC)-transporter P-glycoprotein is regulated by the RNA interference (25-27).

In the present study we observed that both $\mathrm{ONC}$ and r-Amph were highly active against DLBCL-derived cell line. Interestingly, the addition of DOX significantly amplified the pro-apoptotic effect against DLBCL cells. Similar effect was also observed for both ONC and r-Amph in Burkitt's lymphoma-derived Raji cell line in combinations with DOX compared to single agents. In the case of ALL cells only ONC+DOX combination showed significantly higher pro-apoptotic effect compared to the single agents. There were no statistical differences when r-Amph was studied. Last but not the least, in the case of cells from CLL patients the combination of ONC, but not r-Amph, with 2-CdA or FA exerted significantly stronger effect than single drugs.

It should be noted that whereas much has been already learned about cytotoxic capabilities of RNases towards cancer cells, the great majority of in vivo and in vitro studies was made with particular emphasis on ONC (28). The cytostatic, cytotoxic and anticancer effects of Amph have not been extensively investigated so far. Additional clinical trials and studies on animal models are crucial to reveal the exact mechanisms of antitumor activity and clinical potential of both RNases. Of particular value would be in vivo studies of their anticancer effectiveness carried on human tumors transplanted in immunocompromised mice.

\section{Acknowledgements}

The study was supported by the grant from Ministry of Science/National Science Centre, Poland (no. 507-18-010) and, in part, by the grant from Medical University of Lodz, Poland (no. 503/8-093-01/503-01).

\section{References}

1. Arnold U and Ulbrich-Hofmann R: Natural and engineered ribonucleases as potential cancer therapies. Biotechnol Lett 28: 1615-1622, 2006.

2. Leland PA and Raines RT: Cancer chemotherapy - ribonucleases to the rescue. Chem Biol 8: 405-413, 2001.

3. Leland PA, Schultz LW, Kim BM, et al: Ribonuclease A variants with potent cytotoxic activity. Proc Natl Acad Sci USA 95: 10407-10112, 1998.

4. Turcotte RF and Raines RT: Interaction of onconase with the human ribonuclease inhibitor protein. Biochem Biophys Res Commun 377: 512-514, 2008.

5. Singh UP, Ardelt W, Saxena SK, et al: Enzymatic and structural characterisation of amphinase, a novel cytotoxic ribonuclease from Rana pipiens oocytes. J Mol Biol 371: 93-111, 2007.

6. Ardelt W, Mikulski SM and Shogen K: Amino acid sequence of an anti-tumor protein from Rana pipiens oocytes and early embryos. Homology to pancreatic ribonucleases. J Biol Chem 266: 245-251, 1991.
7. Dyer KD and Rosenberg HF: The RNase a superfamily: generation of diversity and innate host defense. Mol Divers 10: 585-597, 2006.

8. Ardelt W, Shogen K and Darzynkiewicz Z: Onconase and amphinase, the antitumor ribonucleases from Rana pipiens oocytes. Curr Pharm Biotechnol 9: 215-225, 2008.

9. Zhao H, Ardelt B, Ardelt W, Shogen K and Darzynkiewicz Z: The cytotoxic ribonuclease onconase targets RNAi (siRNA). Cell Cycle 7: 3258-3261, 2008.

10. Mikulski SM, Viera A, Ardelt W, et al: Tamoxifen and trifluoroperazine (Stelazine) potentiate cytostatic/cytotoxic effects of P-30 protein, a novel protein possessing anti-tumor activity. Cell Tissue Kinet 23: 237-346, 1990.

11. Rybak SM, Pearson JW, Fogler WE, et al: Enhancement of vincristine cytotoxicity in drug-resistant cells by simultaneous treatment with onconase, an antitumor ribonuclease. J Natl Cancer Inst 88: 747-753, 1996.

12. Smolewski P, Bedner E, Du L, Hsieh TC, Wu JM, Phelps DJ and Darzynkiewicz Z: Detection of caspases activation by fluorochrome-labeled inhibitors: multiparameter analysis by laser scanning cytometry. Cytometry 44: 73-82, 2001.

13. Ardelt W, Ardelt B and Darzynkiewicz Z: Ribonucleases as potential modalities in anticancer therapy. Eur J Pharmacol 625: 181-189, 2009.

14. Zwolińska M and Smolewski P: Onconase: a ribonuclease with antitumor activity. Post Hig Med Dosw 64: 58-66, 2009.

15. Michaelis M, Cinatl J, Anand P, et al: Onconase induces caspaseindependent cell death in chemoresistant neuroblastoma cells. Cancer Lett 250: 107-116, 2007.

16. Pozarowski P, Huang X, Halicka DH, Lee B, Johnson G and Darzynkiewicz Z: Interactions of fluorochrome-labeled caspase inhibitors with apoptotic cells. A caution in data interpretation. Cytometry A 55: 50-60, 2003.

17. Ardelt B, Ardelt W, Pozarowski P, et al: Cytostatic and cytotoxic properties of amphinase: a novel cytotoxic ribonuclease from Rana pipiens oocytes. Cell Cycle 6: 3097-3102, 2007.

18. Matoušek J: Ribonucleases and their antitumor activity. Comp Biochem Physiol 129C: 175-191, 2001.

19. Fredman P: Glycosphingolipid tumor antigens. Adv Lipid Res 25: 213-234, 1993.

20. Johnson RJ, Chao T-Y, Lavis LD, et al: Biochemistry 46: 10308-10316, 2007.

21. Mikulski SM, Viera A, Darzynkiewicz Z, et al: Synergism between a novel amphibian oocyte ribonuclease and lovastatin in inducing cytostatic and cytotoxic effects in human lung and pancreatic carcinoma cell lines. Br J Cancer 66: 304-310, 1992.

22. Deptala A, Halicka HD, Ardelt B, et al: Potentiation of tumor necrosis factor induced apoptosis by onconase. Int $\mathrm{J}$ Oncol 13: 11-16, 1998.

23. Ita M, Halicka HD, Tanaka T, Kurose A, Ardelt B, Shogen K and Darzynkiewicz Z: Remarkable enhancement of cytotoxicity of onconase and cepharanthine when used in combination on various tumor cell lines. Cancer Biol Ther 7: 1104-1108, 2008.

24. Ardelt B, Ardelt W and Darzynkiewicz Z: Cytotoxic ribonucleases and RNA interference (RNAi). Cell Cycle 2: 22-24, 2003.

25. Ikemura K, Yamamoto M, Miyazaki S, Mizutani H, Iwamoto T and Okuda M: MicroRNA-145 post-transcriptionally regulates the expression and function of P-glycoprotein in intestinal epithelial cells. Mol Pharmacol 83: 399-405, 2013.

26. Zhu X, Li Y, Shen H, Li H, Long L, Hui L and Xu W: miR-137 restoration sensitizes multidrug-resistant MCF-7/ADM cells to anticancer agents by targeting YB-1. Acta Biochim Biophys Sin (Shanghai) 45: 80-86, 2013.

27. Bao L, Hazari S, Mehra S, Kaushal D, Moroz K and Dash S: Increased expression of P-glycoprotein and doxorubicin chemoresistance of metastatic breast cancer is regulated by miR-298. Am J Pathol 180: 2490-2503, 2012.

28. Costanzi J, Sidransky D, Navon A, et al: Ribonucleases as a novel pro-apoptotic anticancer strategy: Review of the preclinical and clinical data for Ranpirnase. Cancer Invest 23: 643-650, 2005. 